This item was submitted to Loughborough's Research Repository by the author.

Items in Figshare are protected by copyright, with all rights reserved, unless otherwise indicated.

\title{
Viscoelastic finite element analysis of the cervical intervertebral discs in conjunction with a multi-body dynamic model of the human head and neck
}

PLEASE CITE THE PUBLISHED VERSION

http://dx.doi.org/10.1243/09544119JEIM421

VERSION

AM (Accepted Manuscript)

\section{PUBLISHER STATEMENT}

This work is made available according to the conditions of the Creative Commons Attribution-NonCommercialNoDerivatives 4.0 International (CC BY-NC-ND 4.0) licence. Full details of this licence are available at: https://creativecommons.org/licenses/by-nc-nd/4.0/

\section{LICENCE}

CC BY-NC-ND 4.0

\section{REPOSITORY RECORD}

Esat, Volkan, and Memis Acar. 2019. "Viscoelastic Finite Element Analysis of the Cervical Intervertebral Discs in Conjunction with a Multi-body Dynamic Model of the Human Head and Neck". figshare.

https://hdl.handle.net/2134/22043. 


\title{
Viscoelastic finite element analysis of the cervical intervertebral discs in conjunction with a multi-body dynamic model of the human head and neck
}

\author{
V Esat ${ }^{1}$ and $M$ Acar $^{2}$ \\ ${ }^{1}$ Department of Computer Science/ RSI, Loughborough University, Loughborough, \\ Leicestershire, UK \\ ${ }^{2}$ Department of Mechanical and Manufacturing Engineering, Loughborough \\ University, Loughborough, Leicestershire, UK
}

\begin{abstract}
This article presents the effects of the frontal and rear-end impact loadings on the cervical spine components by using a multibody dynamic model of the head and neck, and a viscoelastic finite element (FE) model of the six cervical intervertebral discs. A threedimensional multi-body model of the human head and neck is used to simulate $15 \mathrm{~g}$ frontal and $8.5 \mathrm{~g}$ rear-end impacts. The load history at each intervertebral joint from the predictions of the multi-body model is used as dynamic loading boundary conditions for the FE model of the intervertebral discs. The results from the multi-body model simulations, such as the intervertebral discloadings in the form of compressive, tensile, and shear forces and moments, and from the FE analysis such as the von Mises stresses in the intervertebral discs are analysed. This study shows that the proposed approach that uses dynamic loading conditions from the multi-body model as input to the FE model has the potential to investigate the kinetics and the kinematics of the cervical spine and its components together with the biomechanical response of the intervertebral discs under the complex dynamic loading history.
\end{abstract}

Keywords: cervical spine, multi-body model, viscoelastic finite element model, frontal impact, rear-end impact

\section{INTRODUCTION}

The cervical spine is a system, composed of several components with varying anatomical and mechanical features, such as the cervical vertebrae, the spinal cord, ligaments, muscles, and intervertebral discs. Recreational activities, degenerative diseases, and vehicle accidents are the main causes of cervical spine disorders such as whiplash, resulting in a huge economic burden of medical and insurance costs and loss of work force. In the UK, soft-tissue neck injuries cost insurers over $£ 1$ billion annually, constituting over 80 per cent of the total cost of personal injury claims [1]. In the USA, around 2 million insurance claims are filed each year owing to neck injuries, costing at least US\$8.5 billion annually [2]. Whiplash injuries are estimated to cost the European Union (EU 15) at least J 10 billion a year [3] whereas for Germany the cost is around J 2 billion [4] annually.

The biomechanics of the cervical spine have been the focus of both experimental and computational research to establish the material properties of its components for a better evaluation of the risks, and to obtain an insight into the causation of whiplash disorders. In delving into the issues associated with cervical spine disorders, volunteer tests are rare, expensive, and limited. Similarly, cadaver tests 
are not representative for most cases. However, computational models can play a significant role in simulating a wide range of dynamic loading conditions. While invitro and in- vivo clinical studies continue to provide vital but limited information, computational techniques such as multi-body and finite element (FE) methods are widely but usually separately used to model and simulate the dynamics of the cervical spine

\section{LITERATURE REVIEW}

In the 1980s, the two-dimensional (2D) lumped parameter model developed by Reber and Goldsmith [5] was extended to three dimensions by Merrill et al. [6]. The model was further improved by Deng and Goldsmith [7]. The resulting model consisted of the head, neck, and upper torso (C1 down to T2) with 15 pairs of passive neck muscles. Validation of this model was carried out by utilizing volunteer and physical model tests. The model was mainly used to simulate 2D whiplash motion as well as three- dimensional (3D) lateral impact conditions. The improved model by Deng and Goldsmith appeared to be the most biofidelic when compared with the previous models; however, it seemed to lack the individual contributions of the ligaments and active muscles in order to achieve better biofidelity.

In the 1990s, de J ager [8] developed a more advanced model of the head and cervical spine in the multi-body software package Madymo. The implementation of active muscles increased the biofidelity of the model. In the early 2000s, van der Horst et al. [9] and van der Horst [10] made further improvements to the de J ager model by increasing the geometric details of the vertebrae, updating the material properties of the soft tissues, and modelling the neck muscles in greater detail. The representation of the intervertebral discs was similar to that of the de J ager model but with improved material properties for flexion, extension, and compression, which possessed non-linear characteristics. The inclusion of contact between spinous processes was another novelty of the model.

Dauvilliers et al. [11] reported the development of an FE model of the human neck, considering the vertebrae and the head as rigid bodies. The material properties of the model elements were then tuned to mimic a response similar to that of Naval Biodynamics Laboratory (NBDL) volunteer tests for frontal and lateral impact. Dauvilliers et al. claimed that the model yielded satisfactory results in most aspects of the lateral and frontal impact situations, while failing to produce satisfactory predictions at some points such as acceleration spikes, which did not fall within the response corridors of the validation data. Nitsche et al. [12] presented a further FE model of the human neck and its validation, where vertebral bodies and the articular cartilages were modelled as deformable entities. The model was linear elastic, while the intervertebral discs were isotropic, and the cartilages and ligaments were anisotropic.

The model reported by Yang et al. [13] included linear viscoelastic discs, with ligaments and muscles possessing only passive behaviour. They claimed that the model was validated with reasonable success against the head and neck drop tests as well as cadaveric sled tests. The head- neck model was combined with a previously developed model of the upper torso and employed to simulate the head and neck interaction with a pre-deployed air bag in order to predict head and neck kinematics, load histories, and ligament forces in order to study the mechanics of the neck under impact scenarios.

Kumaresan et al. [14-16] conducted various studies to obtain a better understanding of various problems associated with the cervical spine, such as the biomechanical responses of the pediatric cervical spine, and osteophyte formation. In their FE material property sensitivity study, $\mathrm{Ng}$ et al. [17] claimed that results of the simulations showed that the variations in the material properties of the disc annulus influenced the internal stresses in the disc significantly. Yoganandan et al. [18] also investigated the response of the cervical spine soft tissue by using FE 
modelling. In this work, the researchers concluded that accurate modelling of anatomic, functional, and biomechanical characteristics of spinal tissues was essential to understand the behaviour of the cervical spine under normal and abnormal conditions such as facetectomy, discectomy, and fusion. A study on softtissue neck injuries was con- ducted by Schmitt et al. [19], using FE modelling to examine the blood vessel pressure effects in the venous plexus.

\section{METHOD}

While multi-body models treat each element as a rigid non-deformablebody, limitingtheir capability to investigate stresses, they are much faster than FE models, which tend to be more complicated and very demanding on computational time. This study, thus, proposes an approach, where a multibody model of the cervical spine is used in conjunction with the FE technique, taking advantage of the best features of both techniques, creating more realistic simulations and reducing the computational time significantly. In this approach, the multi-body method is used to investigate the kinetics and kinematics of the cervical spine under specific loading conditions, determining loading history on spinal elements, which in turn are employed in the FE model as boundary conditions to determine the stress state of the intervertebral discs. This approach is based on the assumption that a biofidelic multi- body model with realistic material properties of the spinal elements can provide realistic kinematic and kinetic output of an occupant undergoing a similar impact. Consequently, forces and moments collected from the multi-body model can potentially be used as loading boundary conditions for stand- alone FE models of the spinal elements, such as intervertebral discs.
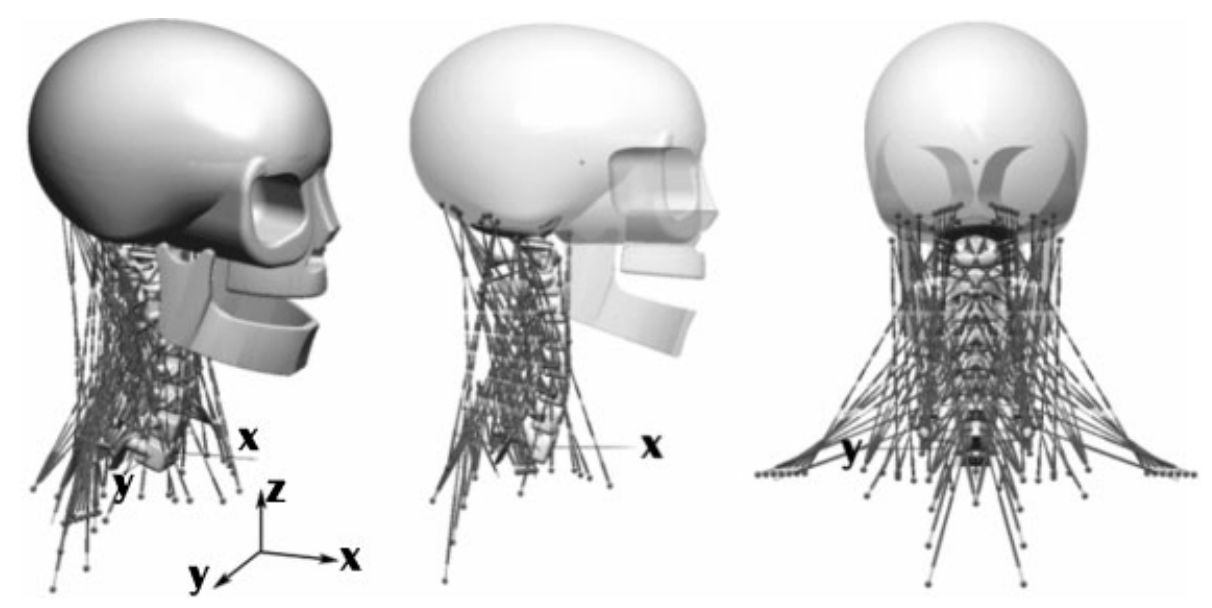

Fig. 1 The multi-body model of the head and neck

In this study, the multi-body and FE models are utilized in order to investigate the effects of two severe impact loadings on the neck, namely $15 \mathrm{~g}$ frontal and $8.5 \mathrm{~g}$ rearend impacts. These two impact conditions are chosen as they represent typical impact severities that can cause injuries such as whiplash, and experimental data [810] are available for these conditions so that the model validation is possible. This approach provides not only a detailed loading history of the impact on each disc but also crucial information on how the disc is affected during the loading, yielding the exact time and location of the high stresses and strains, while indicating the risk levels of the healthy discs under the investigated dynamic loading conditions.

\subsection{The multi-body model}

The multi-body model used in this research was previously developed by van Lopik and Acar [20], and represents the head and neck of a 50th percentile adult in an upright sitting posture, the cervical vertebrae column representing the natural lordosis of the neck with midsagittal symmetry assumed (Fig. 1). The 50th 
percentile adult human head and neck model's features are based on the averages of various adult male and female cervical spine data [20]. The model is constructed using the rigid-body dynamics package MSC.visualNastran 4D 2001 R2 from MSC Software, California, USA. The model consists of nine rigid bodies with detailed geometry representing the head, seven cervical vertebrae, and the first thoracic vertebrae. The material properties of the soft tissue and the rigid bodies are based on the most recent experimental data reported in the literature [18, 21, 22] and data used by de J ager [8] and van der Horst [10]. Nineteen muscle groups of the head and neck are incorporated in the model.

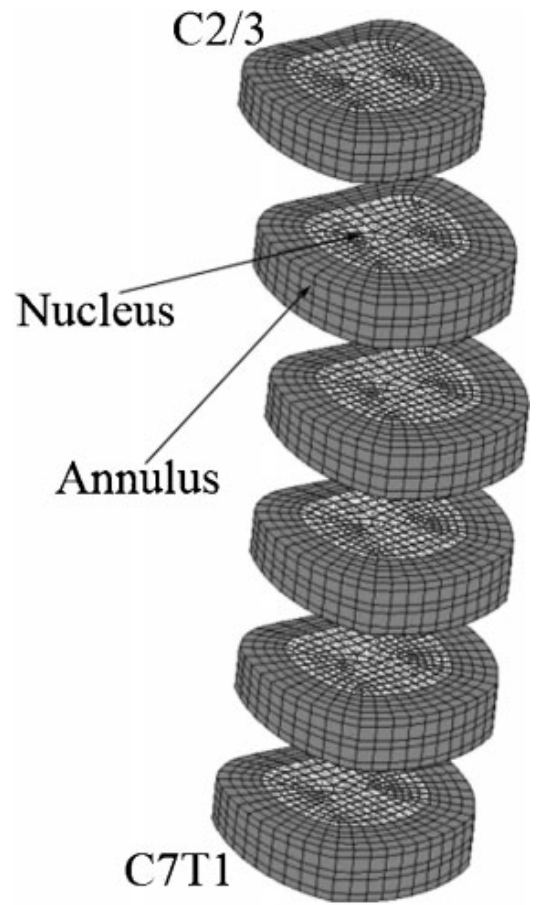

Fig. 2 The FE model of the cervical discs

Table 1 Anatomical properties of the intervertebral discs in the FE model

\begin{tabular}{lllll}
\hline $\begin{array}{l}\text { Intervertebral } \\
\text { disc }\end{array}$ & $\begin{array}{l}\text { Anterior disc height } \\
(\mathrm{mm})\end{array}$ & $\begin{array}{l}\text { Posterior disc height } \\
(\mathrm{mm})\end{array}$ & Disc width (mm) & $\begin{array}{l}\text { Disc depth } \\
(\mathrm{mm})\end{array}$ \\
\hline C2- C3 & 4.8 & 3.4 & 16.9 & 15.0 \\
C3- C4 & 5.3 & 3.3 & 17.1 & 15.2 \\
C4- C5 & 5.5 & 3.0 & 17.5 & 15.5 \\
C5- C6 & 5.4 & 3.0 & 19.4 & 17.4 \\
C6- C7 & 5.2 & 3.3 & 22.0 & 18.5 \\
C7- T1 & 4.7 & 3.5 & 23.4 & 16.8 \\
\hline
\end{tabular}

Muscle mechanics is handled by an external application called Virtual Muscle v. 3.1.5, developed at the Alfred E. Mann Institute at the University of Southern California, USA. Virtual Muscle runs within MATLAB and Simulink, by Mathworks, Inc., USA, providing both passive and active muscle behaviour [23]. Muscle morphometry and fibre-type composition of the various muscles of the neck are based on values reported in the literature[24-28] and investigations of van derHorst et al. [9], van der Horst [10], and Vasavada et al. [29]. The intervertebral discs are incorporated as bushing elements, which allow for six translational and rotational degrees of freedom governed by viscoelastic springdamper relationships. 
Thehead- neckmodel has been evaluated to check the accuracy of the individual components, motion segments, and the model as a whole in response to different loading conditions [20]. The completed model has been validated against experimental results, ranging from the individual motion segment response to the dynamic response of the whole head- neck model to frontal, lateral, and rearend impacts [30]. The model has been used to simulate the frontal and lateral sled acceleration tests per- formed at the NBDL using human volunteers [8-10]. Good agreement was seen for both impact directions [30]. The model has also been implemented without musculature to simulate bench-top trauma experiments using cadaveric isolated cervical spine specimens. The model also successfully reproduced the characteristic 'whiplash' motion and resulting head and vertebral rotations and displacements seen in the experimental results for rear impact accelerations [30].

\subsection{The finite element model}

In order to investigate the effects of the dynamic impact loading on the intervertebral discs, a 3D biofidelic viscoelastic FE model of the six discs (C2- C3, C3- C4, C4- C5, C5- C6, C6- C7, and C7- T1) inthe cervical spine is developed by using the FEA software MSC.Marc/ Mentat 2000 from MSC Software, California, USA (Fig. 2). The dimensions, positions, and the orientations of the discs are taken from the quantitative anatomy of the cervical spine [31, 32] as provided in Table 1 . The relations between the intervertebral spacing and the vertebral body height in the anterior posterior and the middle regions are used to build the FE models. Intervertebral discs are modelled as eight-node brick elements, the material properties of which are adapted from literature [13, 18, 33- 35] as summarized in Table 2. Each disc model consists of 1815 elements and 938 nodes. The discs are modelled and analysed as non-linear contact bodies by using the automatic timestepping option to simulate the dynamic loadings realistically. The intervertebral disc is mainly composed of two parts: nucleus pulposus and annulus fibrosus. All annulus fibrosus bands are modelled with a fibre orientation of $30 \mathrm{u}$ with respect to the lateral plane. The fibres are in opposite alternating directions in two adjacent bands. Although the segments of the vertebral bodies, such as the cortical shell and the end plate, are not included in the proposed FE model of the cervical discs, the FE models of some simplified vertebral bodies are built and used only for validation purposes.

Table 2 Material properties of the intervertebral discs in the FE model

\begin{tabular}{llll}
\hline Relaxation of & Shear relaxation modulus & Bulk relaxation modulus & $\begin{array}{l}\text { Relaxation time } \\
\text { constant }(\mathrm{s})\end{array}$ \\
\hline Annulus matrix & $\mathrm{g}_{1}=0.399$ & $\mathrm{k}_{1}=0.399$ & $\mathrm{t}_{1}=3.45$ \\
$\mathrm{E}=8.0 \mathrm{MPa}$ & $\mathrm{g}_{2}=0.000$ & $\mathrm{k}_{2}=0.300$ & $\mathrm{t}_{2}=100$ \\
$\mathrm{v}=0.35$ & $\mathrm{~g}_{3}=0.361$ & $\mathrm{k}_{3}=0.149$ & $\mathrm{t}_{3}=1000$ \\
& $\mathrm{~g}_{4}=0.108$ & $\mathrm{k}_{4}=0.150$ & $\mathrm{t}_{4}=5000$ \\
Nucleus pulposus & $\mathrm{g}_{1}=0.638$ & $\mathrm{k}_{1}=0.0$ & $\mathrm{t}_{1}=0.141$ \\
$\mathrm{E}=0.5 \mathrm{MPa}$ & $\mathrm{g}_{2}=0.156$ & $\mathrm{k}_{2}=0.0$ & $\mathrm{t}_{2}=2.21$ \\
$\mathrm{v}=0.49$ & $\mathrm{~g}_{3}=0.120$ & $\mathrm{k}_{3}=0.0$ & $\mathrm{t}_{3}=39.9$ \\
& $\mathrm{~g}_{4}=0.0383$ & $\mathrm{k}_{4}=0.0$ & $\mathrm{t}_{4}=266$ \\
& $\mathrm{~g}_{5}=0$ & $\mathrm{k}_{5}=0.0$ & $\mathrm{t}_{5}=500$ \\
\hline
\end{tabular}

The FE model is validated using the published experimental data [33], in compression and flexion- extension. First, a C4- C6 segment model is built in order to comply with the experimental set-up. There- fore, for this purpose only, vertebral bodies are built with the end plates, which surround the discs C4- C5 and C5- C6. Then, the model is subjected to two different loadings: first, $1 \mathrm{~mm}$ axial compression and, second, $1600 \mathrm{~N}$ $\mathrm{mm}$ flexion and extension moments together with a $73.6 \mathrm{~N}$ axial compressive 
preload. The results from the $1 \mathrm{~mm}$ axial compression loading are given in Fig. 3 . For the latter loading case, the FE model yields a rotation of $7.46 \mathrm{u}$ for the flexion moment while the experimental results show $7.02 \mathrm{u}$ with $2.23 \mathrm{u}$ standard deviation. For extension moment loading, the rotation prediction from the FE model is 5.37u, while the experimental results yield $4.80 \mathrm{u}$ with $1.41 \mathrm{u}$ standard deviation. The results from the FE models appear to be in good agreement with the experimental data. As the material properties of all discs are the same, the only difference being the geometries, it is concluded that the validation for the selected discs provides a reasonable set of data to be confident about the FE models of the remaining discs. The strength of the FE model lies in providing the complete set of cervical discs with realistic dimensions and viscoelastic representation.

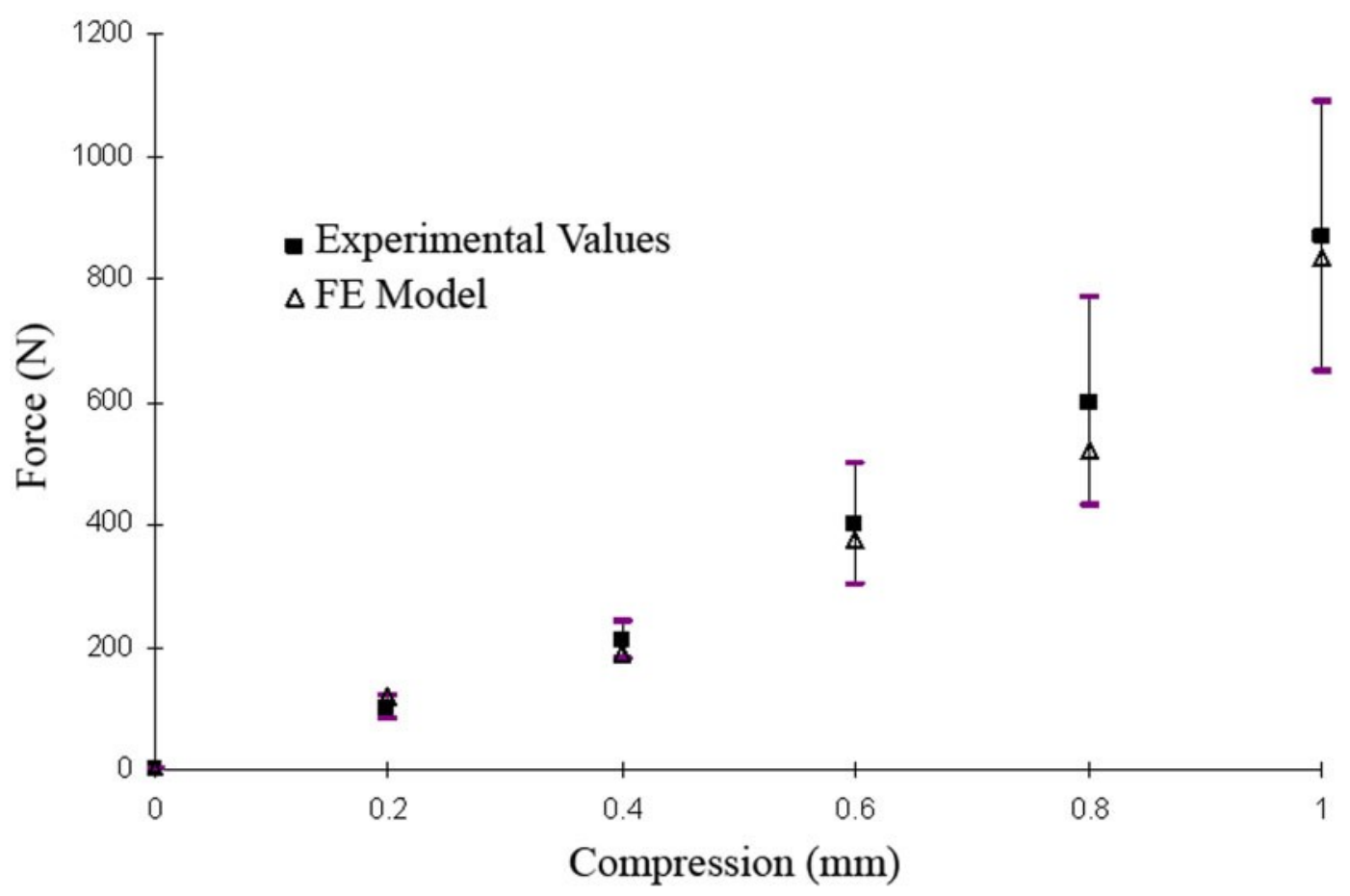

Fig. 3 Validation of the FE disc via comparison of force-compression behaviour of the model with experimental data

\section{RESULTS}

The resulting motions of the multi-body head-neck model simulation when subjected to $15 \mathrm{~g}$ frontal and $8.5 \mathrm{~g}$ rear-end impacts are given in Fig. 4 . The corresponding intervertebral disc loads for the first $200 \mathrm{~ms}$ period as depicted in Figs 5 and 6 are used as the force boundary conditions for the FE model of the discs. In both figures, the disc forces $F_{x}$ and $F_{z}$ are shown on the vertical axis on the left-hand side and the moment $M_{y}$ on the vertical axis on the right-hand side. Figure 5 shows that the disc forces and moments for the $15 \mathrm{~g}$ frontal impact case begin to develop at around 70-80 ms whereas, for the rear- end impact case in Fig. 6, they develop starting from 20-30 ms. In the FE model, the disc forces $F_{x}$ and $F_{z}$ are applied on to the top surface of the disc as a distributed surface load by taking the surface area of the individual disc into consideration, whereas the moment $\mathrm{M}_{\mathrm{y}}$ is applied as a distributed couple moment. The predicted results of the maximum von Mises stresses in the annulus for both frontal and rear-end impact situations are depicted in Fig. 7. The intradiscal pressures occur- ring in the nuclei of the discs display similar patterns to the stress distribution of the annuli for both frontal and rear impact cases. However, for the specific impact conditions investigated, the stress levels in the annuli appear to be at least an order of magnitude higher than the pressure in the nuclei. For both stress distributions and the intradiscal pressures, 
rear-end impact stresses peak earlier, around $120-130 \mathrm{~ms}$, than the frontal impact stresses, which peak at around $180 \mathrm{~ms}$. In the frontal impact case, the stresses also show an earlier peak of much smaller magnitude at around $100 \mathrm{~ms}$.
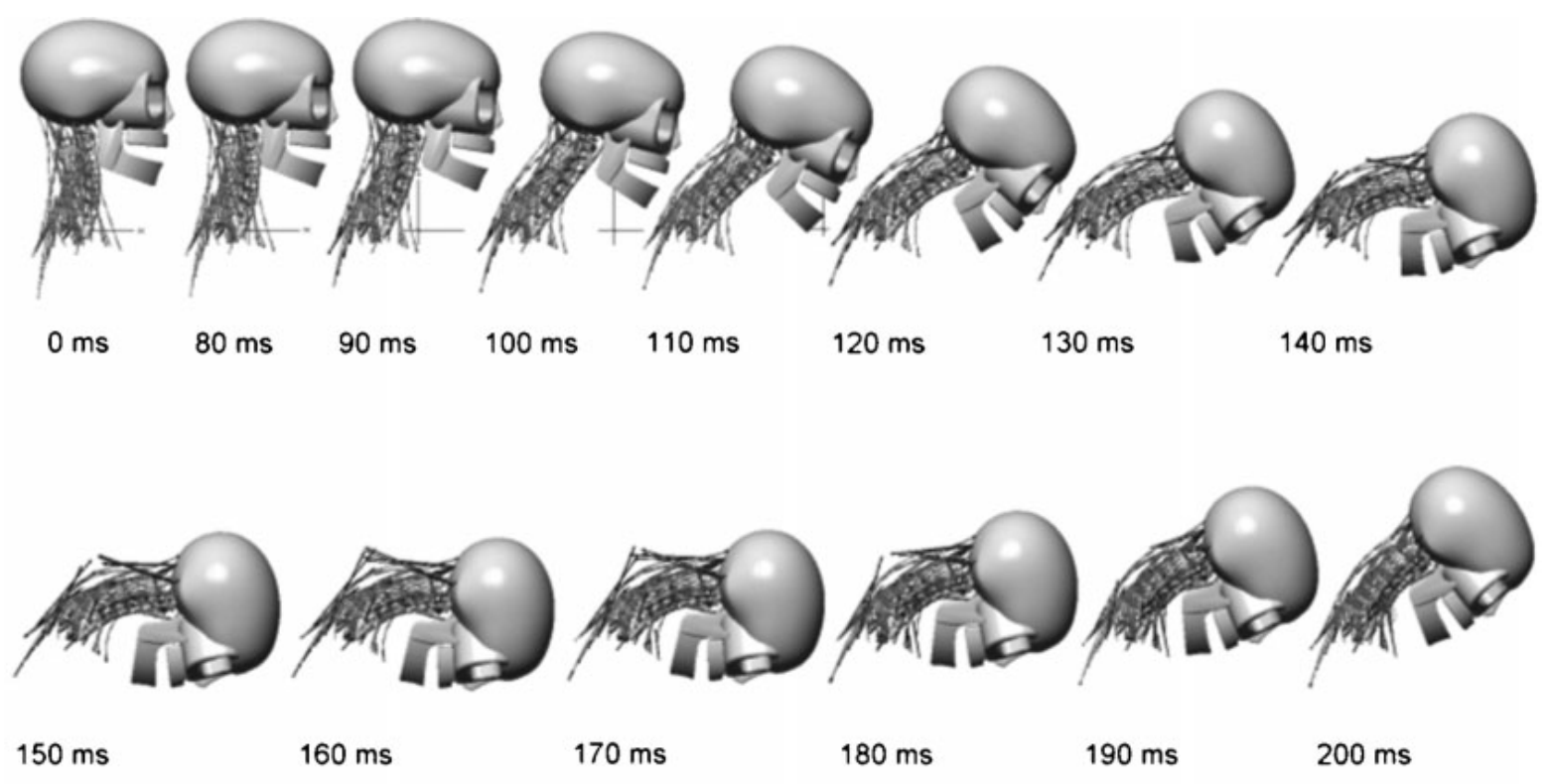

(a)
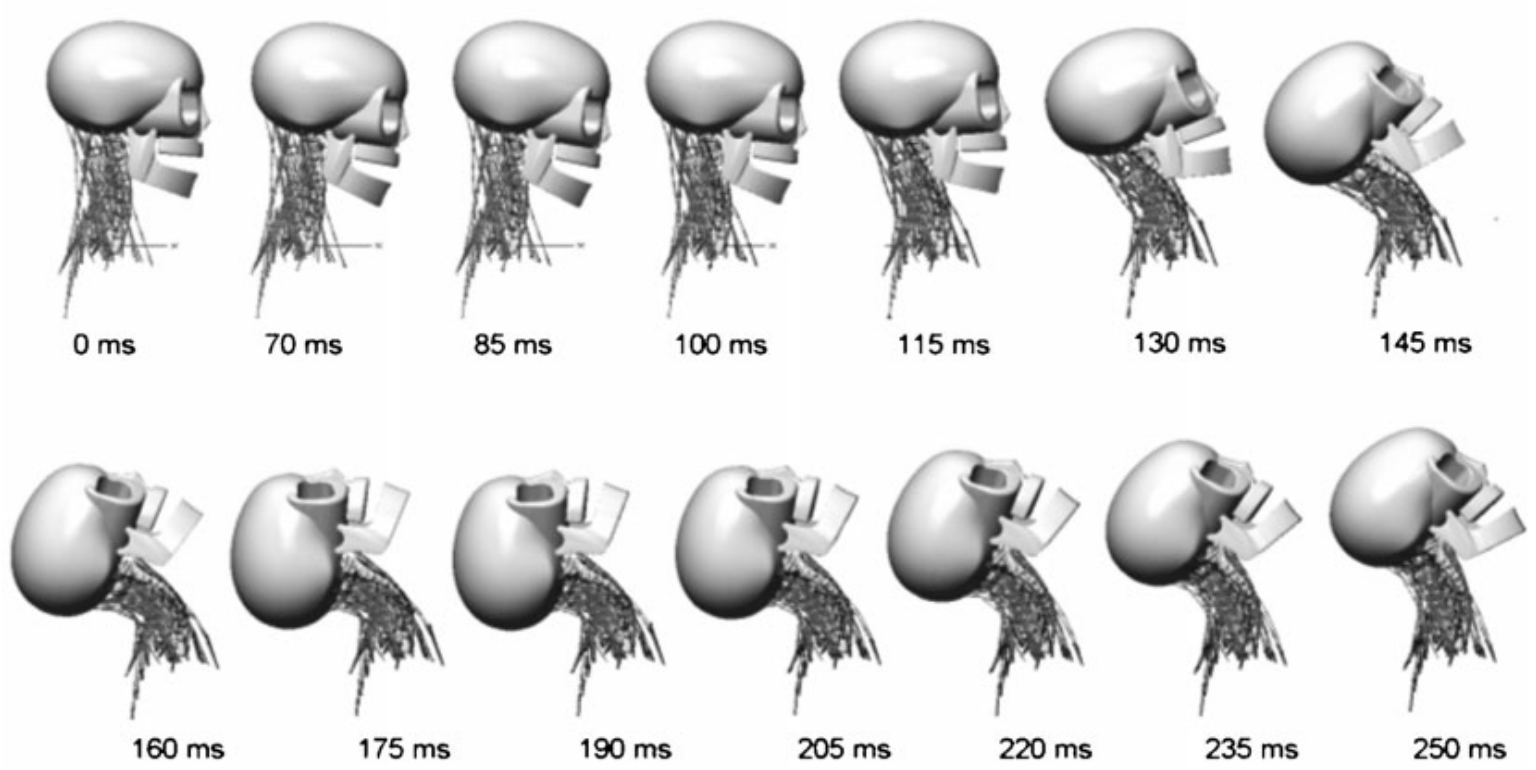

(b)

Fig. 4 Multi-body model simulations for (a) the frontal impact and (b) the rearend impact 
$\mathrm{C} 2 / 3$

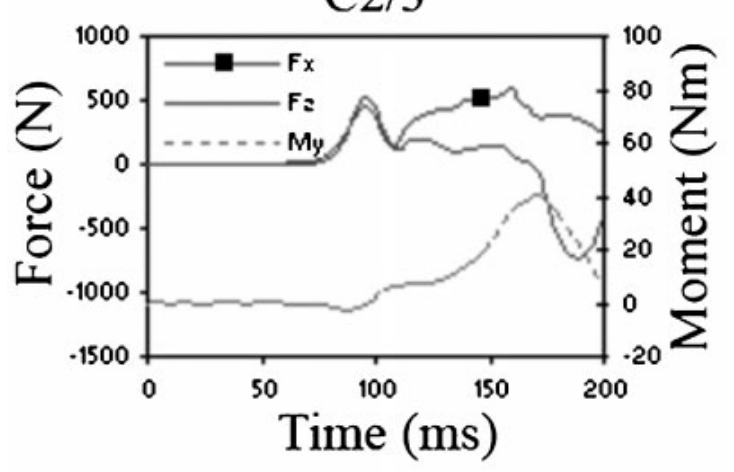

$\mathrm{C} 4 / 5$

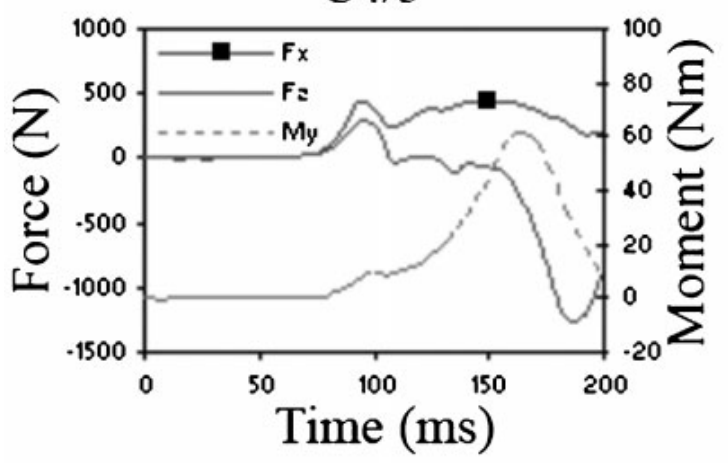

$\mathrm{C} 6 / 7$

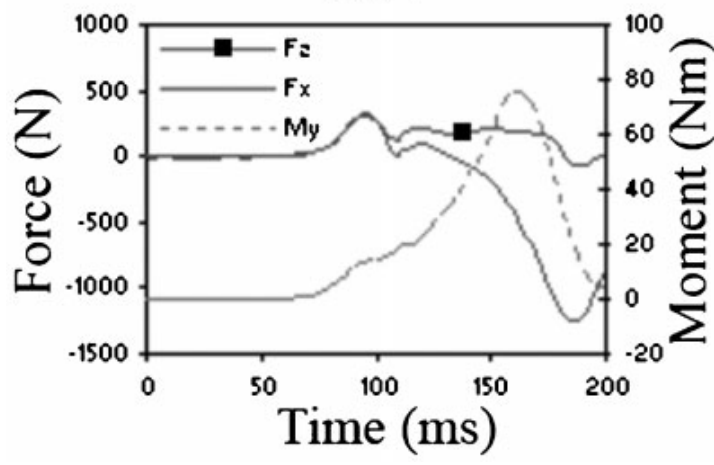

$\mathrm{C} 3 / 4$

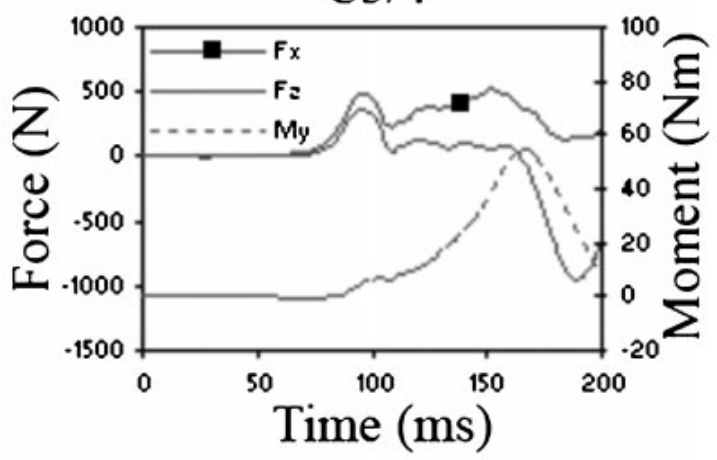

$\mathrm{C} 5 / 6$

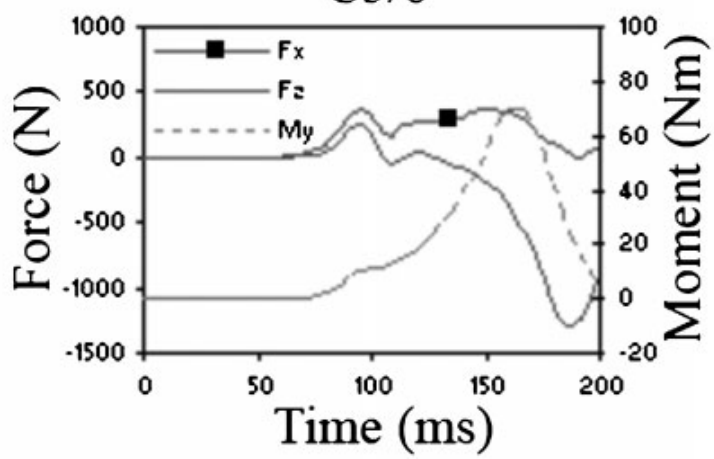

C7T1

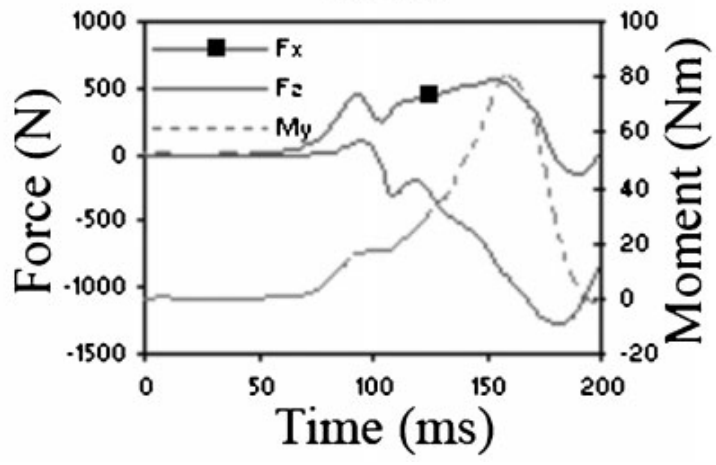

Fig. 5 Intervertebral disc loadings in terms of $F_{x}, F_{z}$ and $M_{y}$ for frontal impact at $15 \mathrm{~g}$

Figure 8 demonstrates a typical development of the von Mises stress distribution in the intervertebral discs for the frontal impact. The stresses begin to concentrate at the posterior and the anterior ends of the C4- C5 disc at about $100 \mathrm{~ms}$. Soon after that, the vertical, mostly compressive loads and the shear forces as given in Fig. 5 become much more dominant on the disc, changing the stress distribution accordingly. Closer investigation of the disc reveals that the stresses on the inferior surface of the disc are higher than the stresses on the superior face and the highest stress concentration happens to be at the posterior end of the inferior surface of the disc. The maximum strains and displacements that occur in each intervertebral disc level for the frontal and rear-end impacts are illustrated in Figs 9 and 10 respectively. Typical responses in terms of equivalent strain and displacement distributions for the C4- C5 disc at the point of highest stresses, i.e. at $180 \mathrm{~ms}$, are illustrated in Figs 11 and 12 respectively. Maximum equivalent strains at $180 \mathrm{~ms}$ occur at the posterior end of the nucleus (Fig. 11), whereas maximum displacements appear to be at the posterior edge of the annulus (Fig. 12). 
$\mathrm{C} 2 / 3$

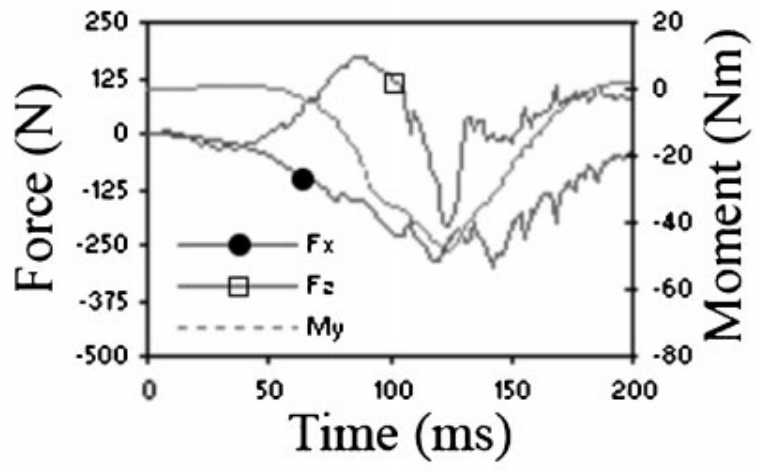

$\mathrm{C} 4 / 5$

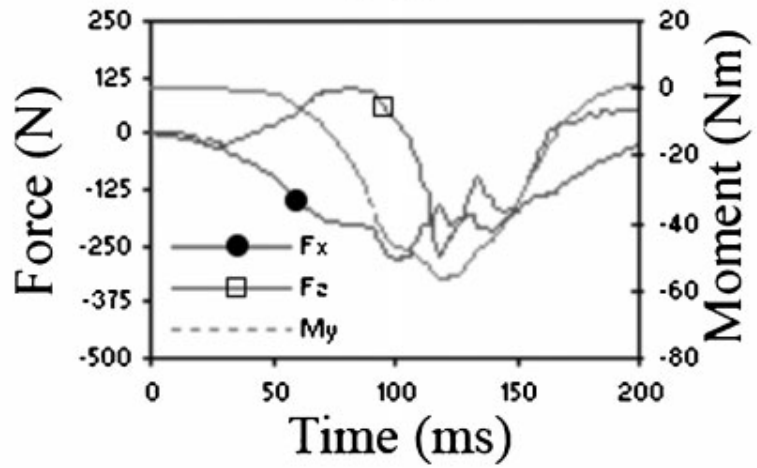

$\mathrm{C} 6 / 7$

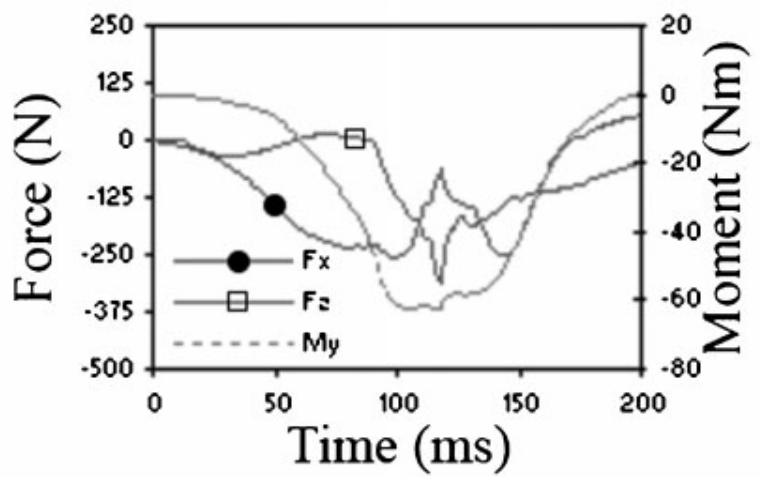

$\mathrm{C} 3 / 4$

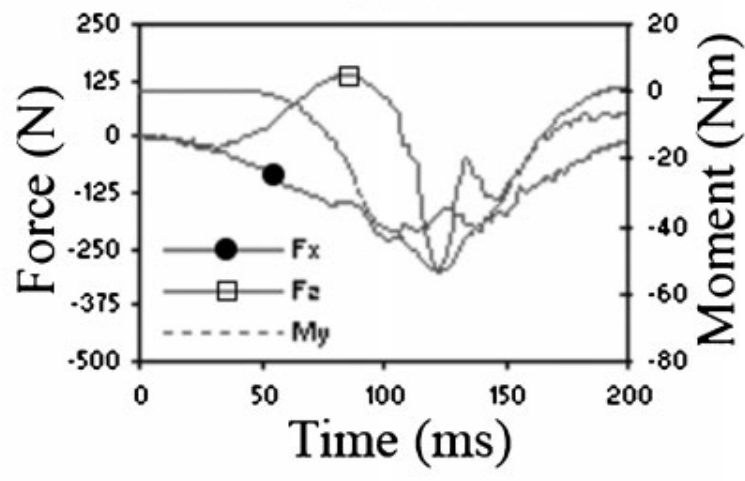

$\mathrm{C} 5 / 6$

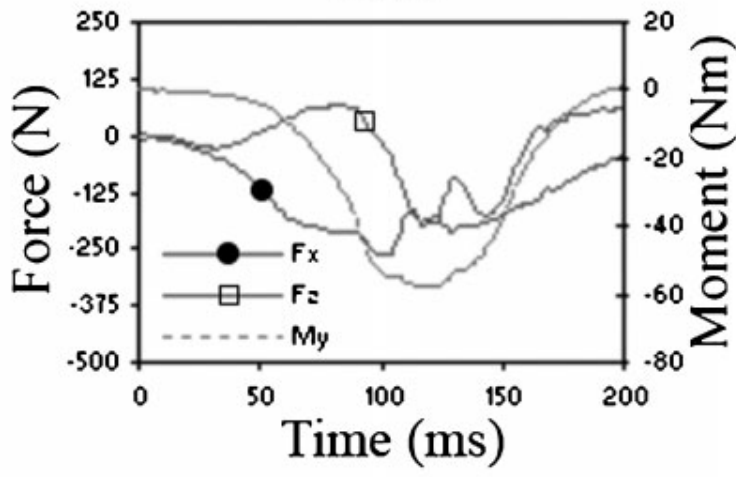

C7T1

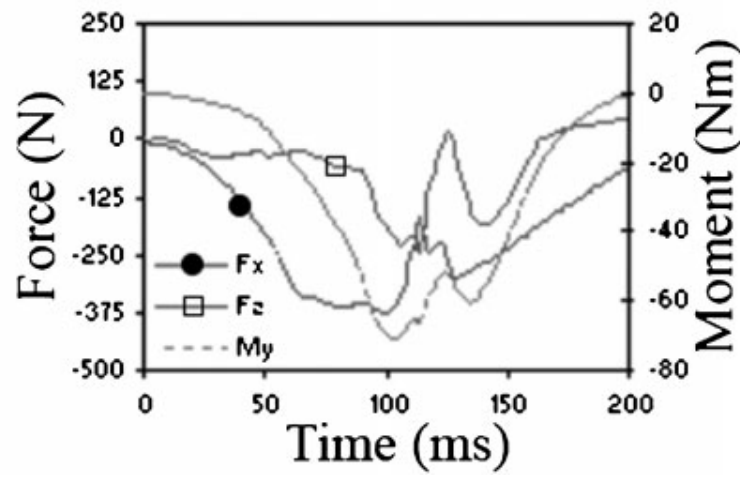

Fig. 6 Intervertebral disc loadings in terms of $F_{x}, F_{z}$ and $M_{y}$ for rear-end impact at $8.5 \mathrm{~g}$

\section{DISCUSSION}

Intervertebral disc loads determined by the multi- body model as shown in Figs 5 and 6 provide an insight into the dynamic behaviour of the head and neck subjected to both frontal and rear-end impacts at $15 \mathrm{~g}$ and $8.5 \mathrm{~g}$ respectively. It should be noted that, owing to the nature of both direct frontal and rear-end impacts, no lateral forces are developed and the moments are experienced about the y axis only, perpendicular to the sagittal plane.

In the case of frontal impact, a peak in anterior shear and tension of the discs at all vertebral levels can be seen at around $100 \mathrm{~ms}$ at maximum neck excursion. In the early stages of impact, i.e. up to $90-100 \mathrm{~ms}$, anterior shear is the dominant force in the C7-T1 disc. Following maximum neck excursion, compression in the discs 
develops, reaching a maximum at all levels at around $180-190 \mathrm{~ms}$. The moment in the discs increases with increasing flexion of the vertebrae and reaches a maximum at all levels at around $160 \mathrm{~ms}$ in conjunction with maximum neck rotation.

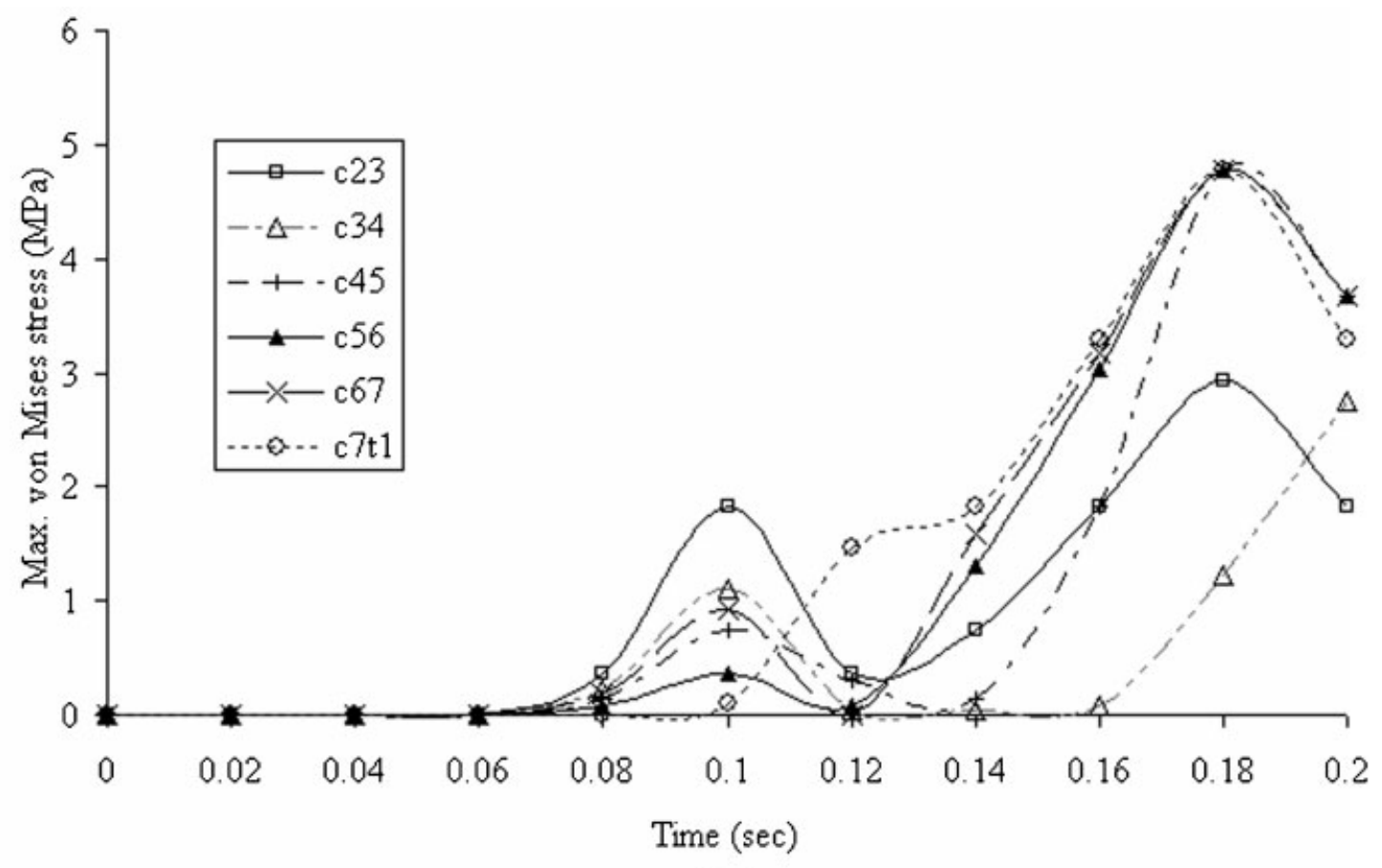

(a)

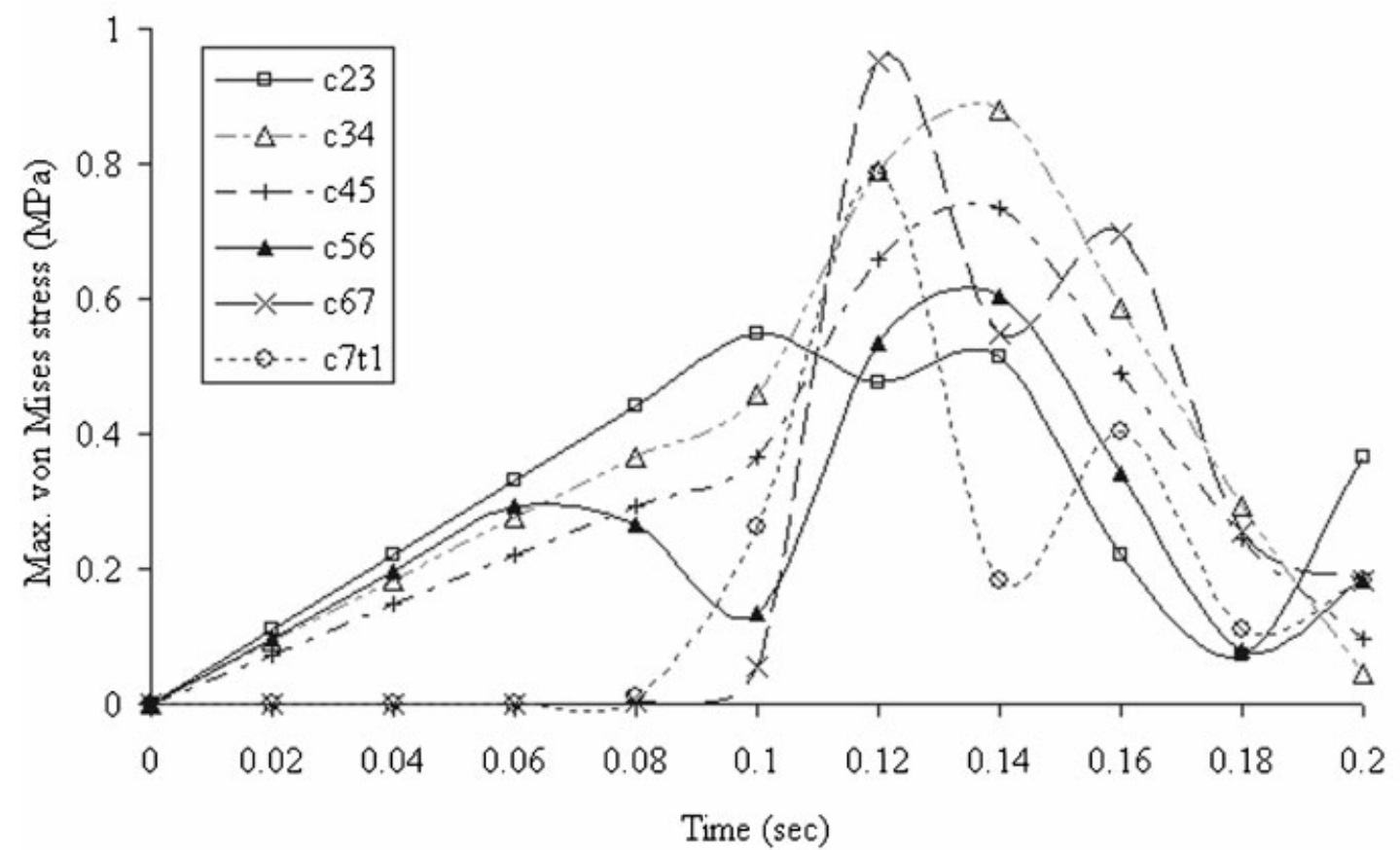

(b)

Fig. 7 FE results: maximum von Mises stresses in the annulus (a) for the frontal impact and (b) for the rear-end impact 


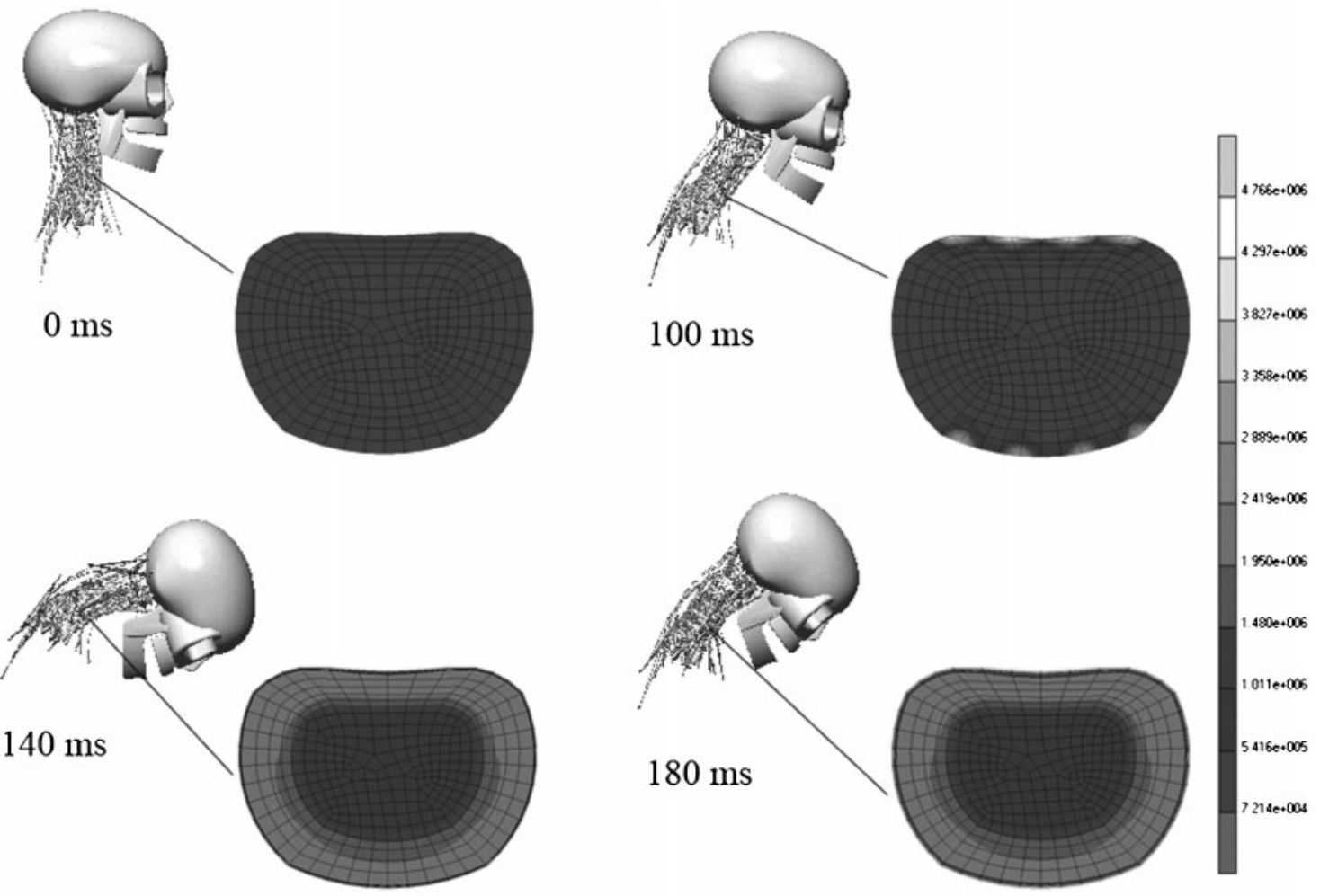

Fig. 8 Illustration of the change in the von Mises stress distribution on the superior face of the $\mathrm{C} 4-\mathrm{C} 5$ disc in the frontal impact case

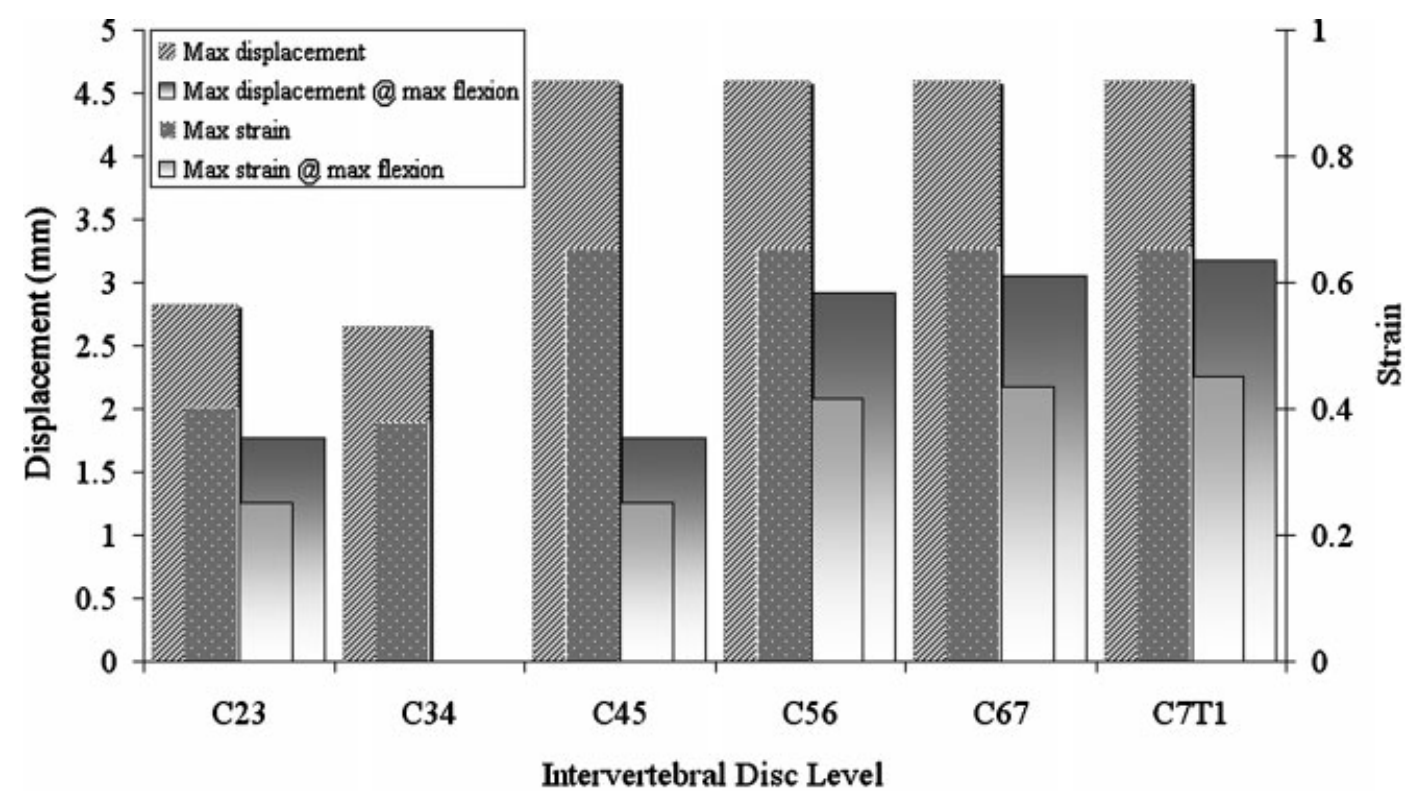

Fig. 9 Maximum strains and displacements in the frontal impact 


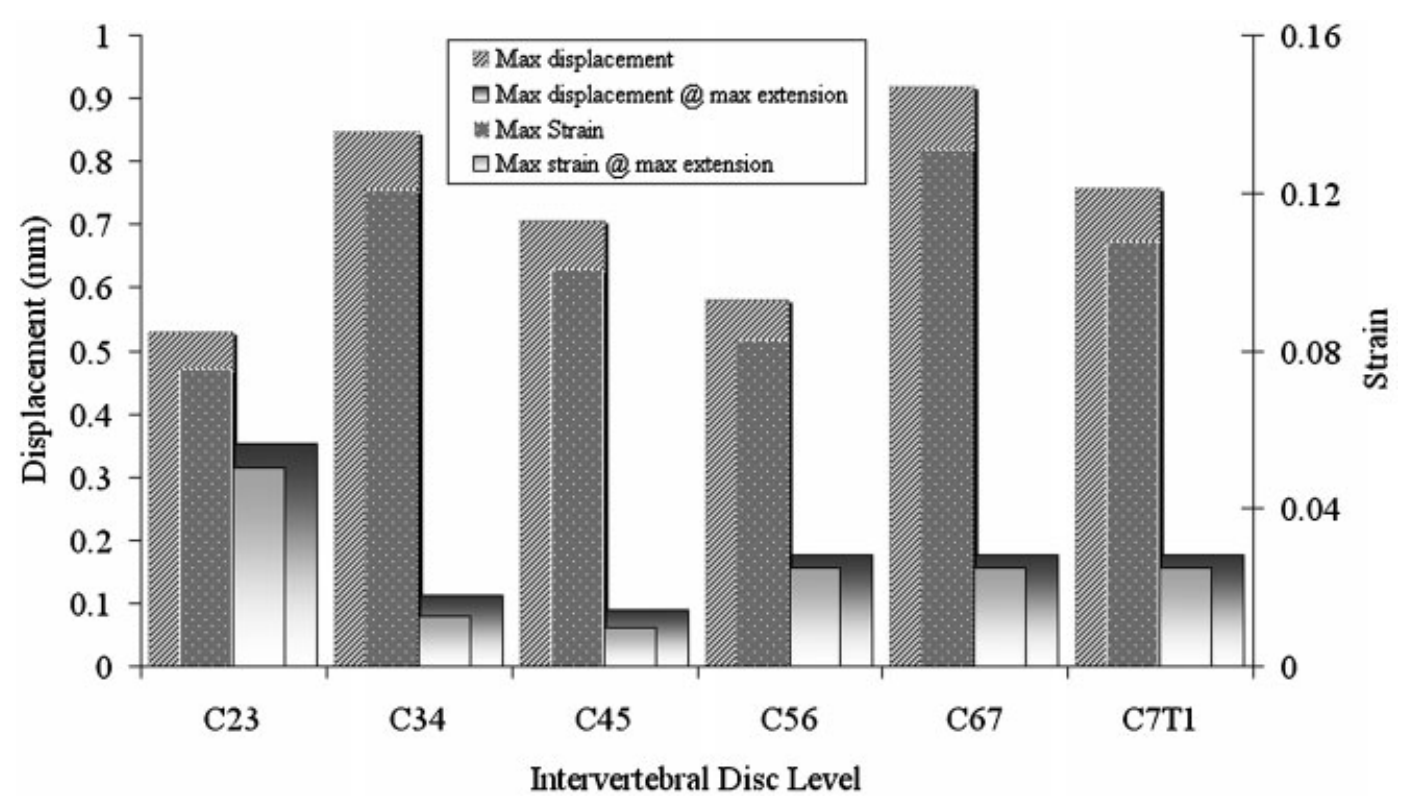

Fig. 10 Maximum strains and displacements in the rear-end impact
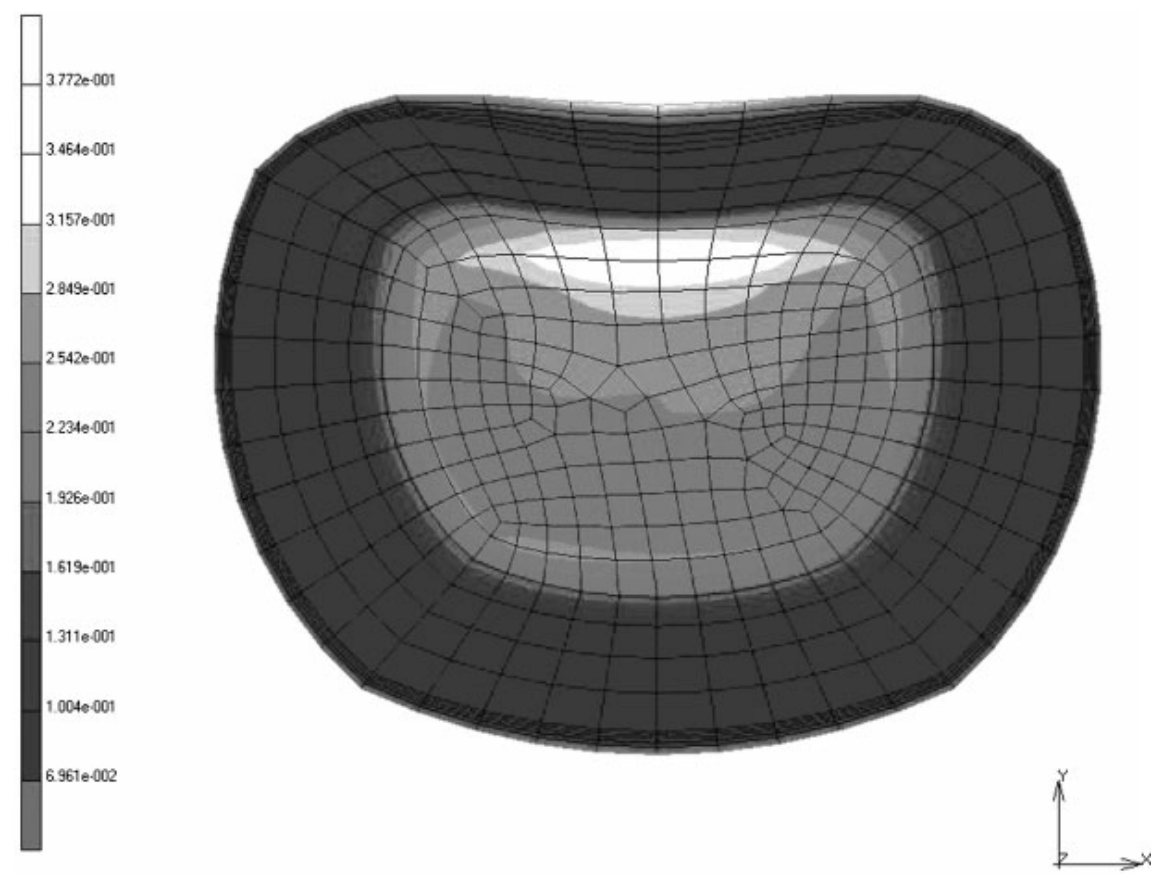

Fig. 11 Maximum equivalent strains in the C4- C5 disc at $180 \mathrm{~ms}$ during the frontal impact

The results from the FE models show that the responses of the annulus and the nucleus have similar characteristics (Fig. 7), but are different in magnitude owing to different material properties and structural features such as the reinforcing effect of the fibres in alternating directions with very small deviations in patterns and tendencies in stress-pressure distributions because of the combined loading of axial and shear forces, and moments. The annulus possesses much higher stresses when compared with the nucleus in both loading cases. 

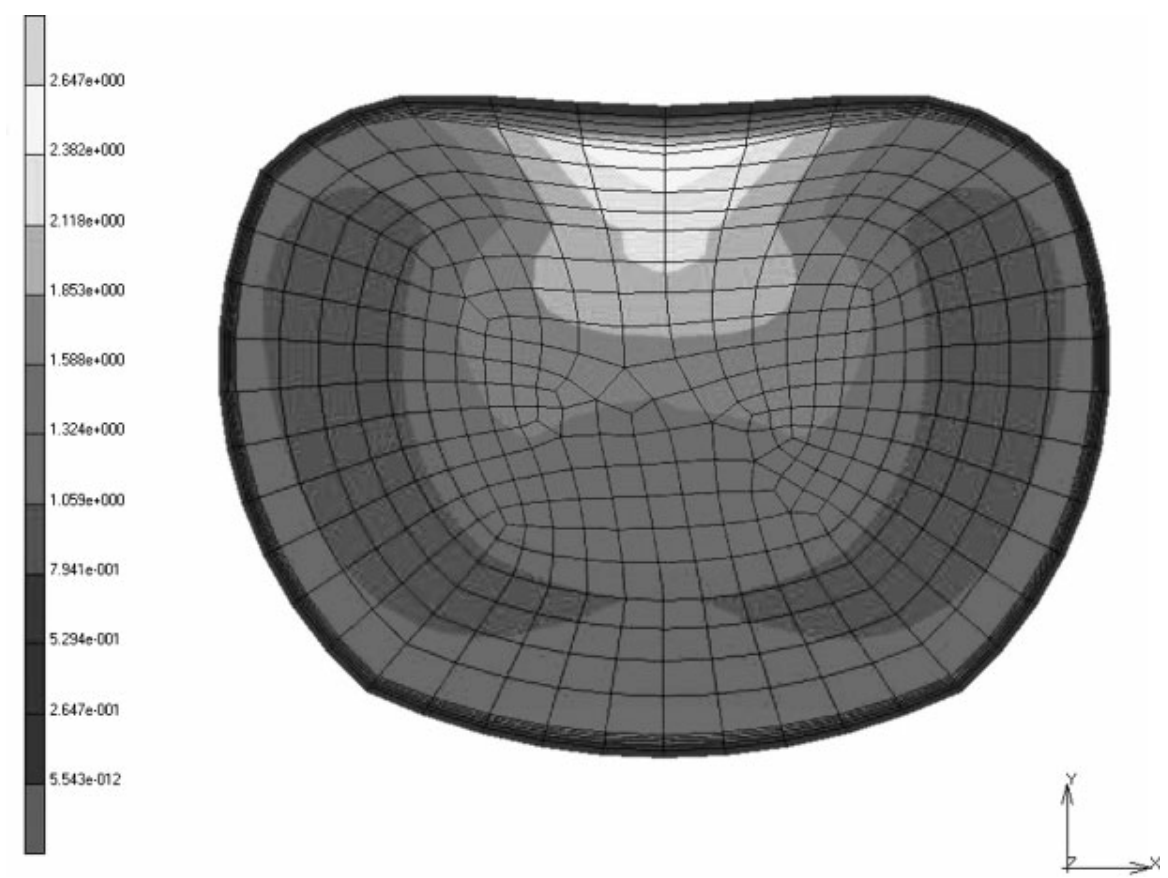

Fig. 12 Maximum displacements in the $\mathrm{C} 4-\mathrm{C} 5$ disc at $180 \mathrm{~ms}$ during the frontal impact

In the frontal impact case, the stresses reach an early and smaller peak at around $100 \mathrm{~ms}$ than the higher peak that occurs at about $180 \mathrm{~ms}$. This is due to the high concentration of the loads, especially the axial force and moment, at these times. At about $100 \mathrm{~ms}$, the topmost disc, C2-C3, possesses a higher maximum von Mises stress, reaching $2 \mathrm{MPa}$, while the lower cervical spine disc, C7- T1, has almost zero stress. In contrast, at $180 \mathrm{~ms}$, the highest maximum von Mises stresses occur in the four lower discs (C4- C5, C5- C6, C6- C7, and C7- T1), whereas the upper two intervertebral discs, C2- C3 and C3- C4, have lower stress values. The peak stress values are approximately $5 \mathrm{MPa}$ at $180 \mathrm{~ms}$. It can be concluded that thefour lower discs (C4- C5, C5- C6, C6- C7, and C7- T1) are more likely to be injured under a similar type of dynamic impact loading. In a similar fashion, the intradiscal pressure in the nucleus gain a maximum value of about $0.22 \mathrm{MPa}$ at $180 \mathrm{~ms}$ in the frontal impact case.

In the rear-end impact case, the peaks in the stress curves occur at about 120- 135 ms. The intervertebral disc C6- C7 possesses the highest maximum von Mises stress of nearly $0.95 \mathrm{MPa}$ at $120 \mathrm{~ms}$, while the lowest stress at this instant is experienced by the topmost disc, C2- C3. The maximum stress in the C6- C7 disc drops significantly at $140 \mathrm{~ms}$, while the disc C3- C4 attains the highest stress of about $0.88 \mathrm{MPa}$. At this instant, the lowest stresses are experienced by the lowest disc, C7T1. Similarly, the maximum intradiscal pressure of $0.05 \mathrm{MPa}$ in the nucleus is sustained by the C6- C7 intervertebral disc at $120 \mathrm{~ms}$, while the topmost disc C2- C3 has the minimum intradiscal pressure value. These results suggest that the stresses at the C6- C7 and C7- T1 discs rise sharply after $80 \mathrm{~ms}$ to reach high peak values, whereas stresses in the other discs rise gradually, reaching peak values at around $140 \mathrm{~ms}$. It can be concluded that the C6-C7 disc is more prone to a possible injury because of the high level of stress and the sharp rise.

Maximum strains and displacements at each intervertebral disc level occur at different times during the frontal impact and are higher in the lower cervical spine discs (Fig. 9). It can be concluded that injuries due to high strain of the soft tissues are more likely to occur at levels C4-C5 to C7- T1 in frontal impact. At the maximum flexion of the neck at about $160 \mathrm{~ms}$, the maximum strains and displacements generally show a similar tendency, increasing from top to bottom discs with the exception of C3- C4, at which displacements are almost zero at this 
particular time step. This finding shows that at the maximum flexion of the cervical spine during frontal impact, which is at a b o u t $160 \mathrm{~ms}$, the C3-C4 disc remains in a neutral state without the effects of intervertebral loadings and moments. In the rear-end impact case, maximum strains and displacements at each level occur at a different time step during the impact and, in contrast with the frontal impact case, do not show a specific pattern within the cervical spine (Fig. 10). The analysis of the results yields that the C6-C7 disc is subjected to maximum strains and displacements among the intervertebral discs during the whole duration of the rear-end impact.

\section{CONCLUSIONS}

This study shows that the proposed approach that simulates the kinematics and kinetics of the human had and neck via multi-body modelling and feeds the loading conditions from these simulations into the FE models of the intervertebral discs is potentially a powerful and versatile method to investigate the dynamics of the whole cervical spine and its components and the mechanical response of the intervertebral discs under complex dynamic loading histories. This approach leads to more realistic simulation of loading conditions, taking advantage of the strengths of both techniques. The simulations also exhibit a cost-effective way of investigating the spinal components and the injury risk levels by providing detailed data on the deformations.

\section{REFERENCES}

1 Avery, M., Giblen, E., Weekes, A. M., and Zuby, D. Developments in dynamic whiplash assessment procedures. In Proceedings of the Conference on Neck Injuries in Road Traffic and Prevention Strategies, Munich, Germany, 5- 6 November 2007, 14 pp.

2 Insurance Institute for Highway Safety, News Release, Rear crash protection in SUVS \& pickups, 2006, available from http:// www.iihs.org/ news/

2006/iihs_news_010806.pdf.

3 EEVC Working Group 20 Report - Working Document 80, Updated state-of-the-art review on Whiplash injury prevention, 2005, available from http:/ / eevc.org/ publicdocs/WG20_Updated_Ad_ Hoc_Report_Final_March_2005.podf.

4 Hell, W., Langwieder, K., Moorahrend, U., Castro, W., Hartwig, E., Schelter, R., and Thoden, U. Standard documentation form for basic diagnostics of cervical spine distortion injuries. In Proceedings of the Whiplash Associated Disorders World Conference, Bern, Switzerland, 2001.

5 Reber, J . G. and Goldsmith, W. Analysis of large head-neck motions. J. Biomechanics, 1979, 12, 211- 222.

6 Merrill, T., Goldsmith, W., and Deng, Y.-C. Three dimensional response of a lumped parameter head- neck model due to impact and impulsive loading. J . Biomechanics, 1984, 17(2), 81- 95.

7 Deng, Y. C. and Goldsmith, W. Response of a human head/ neck/ upper-torso replica to dynamic loading - II. Analytical/ numerical model. J. Bio- mechanics, 1987, 20(5), 471- 486.

8 De J ager, M. K. J . Mathematical head-neck models for acceleration impacts. PhD Thesis, Technical University of Eindhoven, Eindhoven, The Netherlands, 1996.

9 van der Horst, M. J., Thunnsissen, J. G. M., Happee, R., Van Haaster, R. M. H. P., and Wismans, J. S. H. M. The influence of muscle activity on the head-neck response during impact. In Proceedings of the 41st Stapp Car Crash Conference, SAE paper 973346, 1997, pp. 487- 508.

10 van der Horst, M. J. Human head neck response in frontal, lateral and rear end impact loading - modelling and validation. PhD Thesis, Technical University of Eindhoven, Eindhoven, The Netherlands, 2002.

11 Dauvilliers, F., Bendjellal, F., Weiss, M., Lavaste, F., and Tarriere, C. Development of a finite element model of the neck. In Proceedings of the 38th Stapp Car Crash 
Conference, SAE paper 942210, 1994, pp. 77-91.

12 Nitsche, S., Krabbel, G., Appel, H., and Haug, E. Validation of a finite-elementmodel of the human neck. In Proceedings of the International Conference on the Biomechanics of impact (IRCOBI), Dublin, Ireland, 11- 13 September 1996, pp. 107- 122 (International Research Council on the Biomimetics of Impacts, Bron).

13 Yang, K. H., Zhu, F., Luan, F., Zhao, L., and Begeman, P. C. Development of a finite element model of the human neck. In Proceedings of the 42nd Stapp Car Crash Conference, SAE paper 983157, 1998, pp. 195- 205.

14 Kumaresan, S., Yoganandan, N., Pintar, F. A., and Maiman, D. J . Finite element modeling of the cervical spine: role of intervertebral disc under axial and eccentric loads. Med. Engng Physics, 1999, 21, 689- 700.

15 Kumaresan, S., Yoganandan, N., and Pintar, F. A. Finite element analysis of the cervical spine: a material property sensitivity study. Clin. Biomechanics, 1999, 14, 41- 53.

16 Kumaresan, S., Yoganandan, N., Pintar, F. A., Maiman, D. J ., and Goel, V. K. Contribution of disc degeneration to osteophyte formation in the cervical spine: a biomechanical investigation. J . Orthop. Res., 2001, 19, 977- 984.

$17 \mathrm{Ng}, \mathrm{H}$. W., Teo, E. C., and Lee, V. S. Statistical factorial analysis on the material property sensitivity of the mechanical responses of the C4-C6 under compression, anterior and posterior shear. J. Biomechanics, 2004, 37, 771- 777.

18 Yoganandan, N., Kumaresan, S., and Pintar, F. A. Biomechanics of the cervical spine Part 2: cervical spine soft tissue responses and biomechanical modelling. Clin. Biomechanics, 2001, 16, 1- 27.

19 Schmitt, K.-U., Muser, M. H., Walz, F. H., and Niederer, P. F. Fluid-structure interaction in the biomechanics of soft tissue neck injuries: a finite element study to analyze blood vessel pressure effects in the venous plexus. Traffic Injury Prev., 2002, 3, 65- 73.

20 van Lopik, D. W. and Acar, M. Development of a multi-body computational model of human head and neck. Proc. IMechE, Part K: J. Multi-body Dynamics, 2007, 221(2), 175- 197.

21 Camacho, D. L., Nightingale, R. W., Robinette, J.J., Vanguri, S. K., Coates, D. J., and Myers, B. S. Experimental flexibility measurements for the development of a computational head- neck model validated for near-vertex head impact. In Proceedings of the 41st Stapp Car Crash Conference, SAE paper973345, 1997, pp. 473486.

22 Yoganandan, N., Kumaresan, S., and Pintar, F. A. Geometric and mechanical properties of human cervical spine ligaments. J . Biomech. Engng, 2000, 122, 623-629.

23 Cheng, E. J., Brown, I. E., and Loeb, G. E. Virtual muscle: a computational approach to understanding the effects of muscle properties on motor control.J . Neurosci. Meth., $2000,101,117-130$.

24 Winters, J. M. and Woo, S. L.-Y. Multiple muscle systems: biomechanicsandmovement organization, 1990 (Springer-Verlag, Berlin).

25 J ohnson, G., Bogduk, N., Nowitzke, A., and House,D. Anatomy and actions of the trapezius muscle.Clin. Biomechanics, 1994, 9, 44- 50.

26 Kamibayashi, L. K. and Richmond, F. J. R. Morphometry of human neck muscles. Spine, 1998, 23(12), 1314- 1323.

27 Richmond, F. J. R., Singh, K., and Corneil, B. D. Neck muscles in the rhesus monkey I. Muscle morphometry and histochemistry. J . Neurosci., 2001, 86, 1717- 1728.

28 Boyd-Clarke, L. C., Briggs, C. A., and Galea, M. P. Comparative histochemical composition of muscle fibres in a pre- and a postvertebral muscle of the cervical spine.J . Anat., 2001, 199, 709- 716.

29 Vasavada, A. N., Li, S., and Delp, S. L. Influence of muscle morphometry and moment arms on the moment-generating capacity of human neck muscles. Spine, 1998, 23(4), 412- 422.

30 van Lopik, D. W. and Acar, M. Dynamic verification of a multi-body computational model of human head and neck for frontal, lateral, and rear impacts. Proc. IMechE, Part K: J . Multi-body Dynamics, 2007, 221(2), 199- 217.

31 Panjabi, M. M., Duranceau, J., Goel, V., Oxland, T., and Takata, K. Cervical 
human vertebrae. Quantitative three-dimensional anatomy of the middle and lower regions. Spine, 1992, 16(8), 861-869.

32 Nissan, M. and Gilad, I. The cervical and lumbar vertebrae and anthropometric model. Engng Medicine, 1984, 13(3), 111- 114.

33 Teo, E. C. and Ng, H. W. Evaluation of the role of ligaments, facets and disc nucleus in lower cervical spine under compression and sagittal moments using finite element method. Med. Engng Physics, 2001,23, 155- 164.

34 Lee, C.-K., Kim, Y. E., Lee, C.-S., Hong, Y.-M., J ung, J .-M., and Goel, V. K. Impact response of the intervertebral disc in a finite-element model. Spine, 2000, 25(19),24312439.

35 Wang, J .-L., Parnianpour, M., Shirazi-Adl, A., and Engin, A. E. Viscoelastic finiteelement analysis of a lumbar motion segment in combined compression and sagittal flexion: effect of loading rate. Spine, 2000, 25(3), 310-318. 